\title{
Determinants of Blood Pressure Control in Hypertensive Diabetic Patients in Rajshahi District of Bangladesh
}

\author{
M. Nazrul Hoque ${ }^{1 *}$, Nazrul Islam Mondal ${ }^{2}$, Sabiha Yasmin Moni ${ }^{3}$ and Rocky Khan Chowdhury ${ }^{4}$ \\ ${ }^{1}$ Department of Demography and Institute for Demographic and Socioeconomic Research, University of Texas, USA \\ ${ }^{2}$ Department of Population Science and Human Resource Development University of Rajshahi, Bangladesh \\ ${ }^{3}$ Department Pharmacology and Therapeutics, Rajshahi Medical College, Rajshahi, Bangladesh \\ ${ }^{4}$ Department of Population Science and Human Resource Development, University of Rajshahi, Bangladesh
}

\begin{abstract}
Background: The main objective of the study is to examine the determinants of High Blood Pressure Control among Hypertensive Diabetic Patients in Rajshahi district of Bangladesh.

Methods: Four hundred and six hypertensive diabetic patients (254 male and 152 female) were interviewed through a structured questionnaire from the Rajshahi Medical College Hospital and Rajshahi Diabetic Center who were receiving medication for hypertension (HTN) and diabetes. Bivariate and multivariate statistical techniques, such as, chi-square $\left(\chi^{2}\right)$ test and logistic regression analysis were used to evaluate the effect of a select group of variables on the probability of controlling HTN.

Results: Among 406 respondents, 259 or $63.8 \%$ of the respondents can control HTN while 147 or $36.2 \%$ cannot control HTN. Among the patients who can controlled HTN almost $63 \%$ are males and $37.0 \%$ are females. The results of the $\chi^{2}$ test and the regression analysis show that the variables selected for the analysis are generally important predictors of HTN control among the diabetic patients.

Conclusion: The prevalence of hypertensive diabetic is increasing rapidly in Bangladesh. It is a chronic disease which can be controlled by regular physical exercise, taking medicine on a regular basis and reducing occupational and mental stress. Educating patients about the effect of the disease will help to control HTN.
\end{abstract}

Keywords: High Blood pressure (HBP); Hypertension (HTN); Hypertensive diabetic patients; Kidney disease

\section{Introduction}

Hypertension (HTN), also known as high blood pressure (HBP), is one of the most common chronic health conditions prevalent in most of the developed countries. Approximately 1 in 3 or 73 million adults in the United States have HBP. Many people suffer from HTN in the developing countries as well. Blood pressure is essential to move blood from the heart through veins and arteries to all other parts of the body. However, when the pressure is too high, it becomes dangerous, making the heart work harder and increasing the risk for heart problems, such as heart attacks and strokes. Many diabetic patients develop HTN, which increases the potential risk for various problems such as kidney disease, diabetes mellitus, renal disease, blindness and many other deadly diseases. No specific cause for HTN is found in $95 \%$ of the cases but it is an extremely common co-morbid condition in diabetes, affecting $20-60 \%$ of patients with diabetes, depending on obesity, ethnicity, and age [1]. Although diabetes mellitus and HTN are not among the top leading causes of deaths, such as cancer and stroke, these two diseases draw attention from the public due to their increasing trends. Diabetes has been ranked the sixth leading cause of deaths which is also known as costly disease [1]. Coronary heart disease (CHD) is projected to be the most common cause of death globally by 2020 [2]. The HTN is one of the most important modifiable risk factors for CHD in Western and Asian populations [3,4]. Studies from India and Bangladesh have shown an increasing trend in the prevalence of HTN [5]. The prevalence of diabetes mellitus and HTN increases with age [6]. It is estimated that more than 220 million people worldwide have diabetes and the number is likely to be more than double by 2030 without any intervention and $80 \%$ of them will be in low and middle income countries. Almost $80 \%$ of diabetes deaths occur in low and middle-income countries [7]. Diabetes increases the risk of coronary events twofold in men and fourfold in women. Hypertensive diabetes patients have approximately twice the risk of cardiovascular disease compared with hypertensive non-diabetic patients. Hypertensive diabetic patients are also at increased risk for diabetes-specific complications including retinopathy and nephropathy along with kidney diseases, diabetic leg ulcers, sexual dysfunction, and sterility.

The prevalence of diabetes is increasing rapidly in the developing countries including Bangladesh. It is a chronic disease which is never cured but a diabetic patient can lead a normal life by controlling the disease through a planned diet, taking appropriate drugs and regular physical exercise. At present, it is estimated that 3.8 million or $4.8 \%$ of people in Bangladesh have diabetes and that number is expected to grow to 7.4 million or $6.1 \%$ of the population by 2025 [8]. This explosion in diabetes prevalence will place Bangladesh among the top ten countries in terms of the number of people living with diabetes by 2025 . The increase in diabetes in Bangladesh is expected to follow global gender patterns, whereby more women than men will live with diabetes. International Diabetes Federation (IDF) and World Health Organization (WHO) predicted that the number of women in the

*Corresponding author: M. Nazrul Hoque, Department of Demography and Institute for Demographic and Socioeconomic Research, University of Texas at San Antonio, 501 West Durango Boulevard, San Antonio, Texas 78207-4415, Tel: 210-458-6530; Fax: 210-458-6541; E-mail: nazrul.hoque@utsa.edu

Received November 25, 2011; Accepted January 12, 2012; Published January 17, 2012

Citation: Hoque MN, Mondal NI, Moni SY, Chowdhury RK (2012) Determinants of Blood Pressure Control in Hypertensive Diabetic Patients in Rajshahi District of Bangladesh. J Biomet Biostat S7:001. doi:10.4172/2155-6180.S7-001

Copyright: (c) 2012 Hoque MN, et al. This is an open-access article distributed under the terms of the Creative Commons Attribution License, which permits unrestricted use, distribution, and reproduction in any medium, provided the original author and source are credited. 
world with diabetes will double in less than 20 years. In Bangladesh, the number of women with diabetes will grow from the current 2 million to 4 million by 2025 and during the same period, men with diabetes will rise from 1.8 million to 3.4 million [9]. At least $10-15 \%$ of Bangladeshis suffer from diabetes and/or HTN, but only the affluent and disciplined can maintain the regimen of diet, regular physical exercise, doctor visits, blood sugar monitoring, and various biochemical laboratory tests needed to prevent disease progression and severe complications. For millions of people in Bangladesh, diabetes is at the root of severe medical complications including eye problems, kidney disease, and foot problems. Importantly, HTN can lead to aneurysms, heart failure; damage to arteries and other ailments. There is a strong epidemiological connection between HTN in diabetes and adverse outcomes of diabetes. The control of HTN in persons with diabetes has been demonstrated to reduce the rate of progression of diabetic nephropathy and reduce the complications of hypertensive nephropathy, neuropathy, and cardiovascular disease. It is found that in the HTN Optimal Therapy (HOT) study, people with diabetes who kept their DBP (Diastolic Blood Pressure) at 80 (vs $90 \mathrm{mmHg}$ ) had 51\% lower risk of experiencing a cardiovascular event [10].

The United Kingdom Prospective Diabetes Study (UKPDS), a 10 -years study of more than 1000 people who had type-2 diabetes and HTN, clearly demonstrated that BP control is an important issue. Aggressive treatment of even mildly elevated BP was shown to be beneficial. The UKPDS showed that lowering BP to a mean level of 144/82 mmHg significantly reduced vision loss, diabetes related deaths, strokes, heart failure, and various micro vascular complications.

To the best of our knowledge no recent studies have been conducted on hypertensive diabetic patients in Bangladesh. The goal of this study is to examine the determinants of high blood pressure control among the diabetes patients in Rajshahi district of Bangladesh. At present, Bangladesh with an estimated 164.4 million people is the seventh most populous country in the world and the district of Rajshahi is the third largest city in the country. Given how this condition affects such an enormous population, we believe the findings of this study will contribute to the current body of knowledge by elucidating the sociodemographic status and clinical characteristics associated with diabetes and HTN control, and help the policymakers, program planners, and other agencies to create more effective public health policy in Bangladesh.

\section{Data and Methods}

Data for this study comes from 406 hypertensive diabetic patients (254 male and 152 female) from the Rajshahi Medical College Hospital and Rajshahi Diabetic Center who are receiving medication for HTN and diabetes. HTN and diabetics were determined by their respective doctors. HTN was determined according to the standard definition of $140 \mathrm{mmHg}$ or more for systolic pressure and $90 \mathrm{mmHg}$ or more for diastolic pressure. HTN controlled was determined by maintaining an average BP of 130/80 $\mathrm{mmHg}$. Three trained research students from the Department of Population Science, University of Rajshahi under the direct supervision of three faculty members collected necessary data. A structured questionnaire was prepared and pretested by a pilot survey (both in English and Bengali). Corrections were made following an evaluation of the pilot survey and a final version of the questionnaire was completed. Bengali version of the questionnaire was used for more accurate data collection. Responses were then converted to English for data entry and analysis with SPSS (Statistical Package for Social Sciences).
Both bivariate and multivariate analyses were performed for this study. In bivariate analysis, proportions were compared using chi-square $\left(\chi^{2}\right)$ test to analyze the significant association of socioeconomic and clinical variables to control HTN. The logistic regression techniques were used to evaluate the effect of a select group of variables on the probability of controlling HTN. When the dependent variable is dichotomous, a logistic regression model is widely used not only to identify the risk factors but also to predict the probability of success. The logistic regression model for the log odds of hypertension control is:

$$
\log \left(\frac{p_{i}}{1-p_{i}}\right)=\alpha+\beta_{i} X_{i 1}+\beta_{2} X_{i 2} \ldots+\beta_{k} X_{i k}
$$

where $\log \left(\frac{p_{i}}{1-p_{i}}\right)$ is simply the conditional odds of controlling hypertension, given the explanatory variables $\left(\mathrm{X}_{\mathrm{i}}\right), \alpha$ is the regression intercept, $\beta$ are regression coefficients, and $X_{i}$ are a set of predictors. $\mathrm{P}$ can be calculated from the following formula:

$$
P_{i}=\frac{\exp \left(\alpha+\beta_{1} x_{i 1}+\beta_{2} x_{i 2}+\ldots \ldots+\beta_{k} x_{i k}\right.}{1+\exp \left(\alpha+\beta_{1} x_{i 1}+\beta_{2} x_{i 2}+\ldots \ldots+\beta_{k} x_{i k}\right.}
$$

Detailed discussions on logistic regression can be found at Logistic Regression using SAS by Paul D. Allison [11].

\section{Dependent and Independent Variables}

The dependent or response variable in this analyses is HTN control among the diabetes patients, coded 1 for controlled and 0 otherwise. To examine the determinants of HTN control among the diabetes patients, we included several independent variables that have been highly associated with the HTN control. Independent variables are grouped into two categories. These are socio-demographic variables and clinical variables that have been shown in earlier studies to be influential in controlling HTN. The socio-demographic variables are: age, sex, education, occupation, and economic conditions. The clinical variables are: irregularity of taking medicine, side effects of medicine, forgetting to take medicine, kidney diseases, regular physical exercises, occupational stress, mental stress, high levels of salt intake, smoking, and physical activity. Studies have shown that the risk of developing high blood pressure increases with age, weight gain, intake of high sodium foods and with heightened anxiety. Others variables may have significant impact on HTN control, but they have been excluded from the analysis, either because they were not adequately measured or they were not included in the data sets.

\section{Results and Discussion}

Distributions of socio-demographic and clinical characteristics of the respondents are given in Table 1. A total of 406 patients were recruited for the present study. Out of 406 patients, 254 or $62.6 \%$ are male and 152 or $37.4 \%$ are female. Among the participants, 259 or $63.8 \%$ can control HTN while 147 or $36.2 \%$ cannot control HTN. Age distributions of respondents differ significantly based on whether respondents can control HTN or not. The young $(\leq 40)$ and the middle age group (41-55 years) can control HTN better than the respondents who are 56 years of age or older. Respondents who are in the middle age group (i.e., 41-55), 67.7\% can control HTN while $32.3 \%$ cannot control HTN. Only $54.7 \%$ of the respondents who are 56 years of age or older can control HTN while $45.3 \%$ cannot control HTN. Among the 259 respondents who can control HTN, only 9.65 percent are from age group 40 or younger, 59.07 percent are in age group 41-45, and 31.27 percent are 56 years of age or older. This suggests that younger people are not serious about health care and it becomes more difficult to 
Citation: Hoque MN, Mondal NI, Moni SY, Chowdhury RK (2012) Determinants of Blood Pressure Control in Hypertensive Diabetic Patients in Rajshahi District of Bangladesh. J Biomet Biostat S7:001. doi:10.4172/2155-6180.S7-001

Page 3 of 5

\begin{tabular}{|c|c|c|c|c|}
\hline \multirow{2}{*}{ Characteristics } & \multicolumn{2}{|c|}{ Hypertension Control } & \multirow[t]{2}{*}{ Respondents (N) } & \multirow[t]{2}{*}{$P$ values* } \\
\hline & Yes & No & & \\
\hline \multicolumn{5}{|c|}{ Demographic and Socioeconomic Characteristics: } \\
\hline $\begin{array}{l}\text { Sex } \\
\text { Female } \\
\text { Male }\end{array}$ & $\begin{array}{l}97(63.8 \%) \\
162(63.8 \%)\end{array}$ & $\begin{array}{l}55(36.2 \%) \\
92(36.2 \%)\end{array}$ & $\begin{array}{l}152(100.0 \%) \\
254(100.0 \%)\end{array}$ & 0.994 \\
\hline $\begin{array}{l}\text { Age group } \\
\text { Adult age }(\leq 40) \\
\text { Middle age }(41-55) \\
\text { Old age }(\geq 56)\end{array}$ & $\begin{array}{l}25(78.1 \%) \\
153(67.7 \%) \\
81(54.7 \%)\end{array}$ & $\begin{array}{l}7(21.9 \%) \\
73(32.3 \%) \\
67(45.3 \%)\end{array}$ & $\begin{array}{l}32(100.0 \%) \\
226(100.0 \%) \\
148(100.0 \%)\end{array}$ & 0.008 \\
\hline $\begin{array}{l}\text { Education } \\
\text { No Education } \\
\text { Primary\& Secondary } \\
\text { College and Above }\end{array}$ & $\begin{array}{l}48(64.0 \%) \\
151(62.7 \%) \\
60(66.7 \%)\end{array}$ & $\begin{array}{l}27(36.0 \%) \\
90(37.3 \%) \\
30(33.3 \%)\end{array}$ & $\begin{array}{l}75(100.0 \%) \\
241(100.0 \%) \\
90(1000 \%)\end{array}$ & 0795 \\
\hline $\begin{array}{l}\text { Work Status/physical activity } \\
\text { level } \\
\text { Extremely inactive } \\
\text { Lightly active } \\
\text { Moderately active } \\
\text { Vigorously active }\end{array}$ & $\begin{array}{l}15(48.5 \%) \\
166(69.5 \%) \\
7(58.3 \%) \\
71(57.3 \%)\end{array}$ & $\begin{array}{l}16(51.5 \%) \\
73(30.5 \%) \\
5(41.7 \%) \\
53(42.7 \%)\end{array}$ & $\begin{array}{l}31(100.0 \%) \\
239(100.0 \%) \\
12(100.0 \%) \\
124(100.0 \%)\end{array}$ & 0.029 \\
\hline $\begin{array}{l}\text { Economic Hardship } \\
\text { No } \\
\text { Yes }\end{array}$ & $\begin{array}{l}67(63.3 \%) \\
192(63.0 \%\end{array}$ & $\begin{array}{l}34(33.7 \%) \\
113(37.0 \%)\end{array}$ & $\begin{array}{l}101(100.0 \%) \\
305(100.0 \%)\end{array}$ & 0.539 \\
\hline \multicolumn{5}{|l|}{ Clinical Characteristics: } \\
\hline $\begin{array}{l}\text { Physical exercise regularly } \\
\text { No } \\
\text { Yes }\end{array}$ & $\begin{array}{l}28(49.1 \%) \\
231(66.2 \%)\end{array}$ & $\begin{array}{l}29(50.9 \%) \\
118(33.8 \%)\end{array}$ & $\begin{array}{l}57(100.0 \%) \\
349(100.0)\end{array}$ & 0.013 \\
\hline $\begin{array}{l}\text { Took Medicine Regularly } \\
\text { No } \\
\text { Yes }\end{array}$ & $\begin{array}{l}176(62.9 \%) \\
83(65.9 \%)\end{array}$ & $\begin{array}{l}104(37.1 \% \\
43(34.1 \%)\end{array}$ & $\begin{array}{l}280(100.0 \%) \\
126(100.0 \%)\end{array}$ & 0.559 \\
\hline $\begin{array}{l}\text { Side Effect of Medicine } \\
\text { No } \\
\text { Yes }\end{array}$ & $\begin{array}{l}251(66.1) \\
8(30.8 \%)\end{array}$ & $\begin{array}{l}129(33.9) \\
18(69.2 \%)\end{array}$ & $\begin{array}{l}380(100.0 \%) \\
26(100.0 \%)\end{array}$ & 0.000 \\
\hline $\begin{array}{l}\text { Forget to take Medicine } \\
\text { No } \\
\text { Yes }\end{array}$ & $\begin{array}{l}198(66.7 \%) \\
61(56.0 \%)\end{array}$ & $\begin{array}{l}99(33.3 \%) \\
48(44.0 \%)\end{array}$ & $\begin{array}{l}297(100.0 \%) \\
109(100.0 \%)\end{array}$ & 0.047 \\
\hline $\begin{array}{l}\text { Kidney Disease } \\
\text { No } \\
\text { Yes }\end{array}$ & $\begin{array}{l}204(68.0 \%) \\
55(51.9 \%)\end{array}$ & $\begin{array}{l}96(32.0 \%) \\
51(48.1 \%)\end{array}$ & $\begin{array}{l}300(100.0 \%) \\
106(100.0)\end{array}$ & 0.003 \\
\hline $\begin{array}{l}\text { Occupational Stress } \\
\text { No } \\
\text { Yes }\end{array}$ & $\begin{array}{l}220(67.1 \%) \\
39(50.0 \%)\end{array}$ & $\begin{array}{l}108(32.9 \%) \\
39(50.0 \%)\end{array}$ & $\begin{array}{l}328(100.0 \%) \\
78(100.0 \%)\end{array}$ & 0.005 \\
\hline $\begin{array}{l}\text { Mental Stress } \\
\text { No } \\
\text { Yes }\end{array}$ & $\begin{array}{l}102(71.3 \%) \\
157(59.7 \%)\end{array}$ & $\begin{array}{l}41(28.7 \%) \\
106(40.3 \%)\end{array}$ & $\begin{array}{l}143(100.0 \%) \\
263(100.0 \%)\end{array}$ & 0.020 \\
\hline $\begin{array}{l}\text { Salt Intake } \\
\text { No } \\
\text { Yes }\end{array}$ & $\begin{array}{l}173(62.7 \%) \\
86(66.2 \%)\end{array}$ & $\begin{array}{l}103(33.8 \%) \\
44(33.8 \%)\end{array}$ & $\begin{array}{l}276(100.0 \%) \\
130(100.0 \%)\end{array}$ & 0.497 \\
\hline $\begin{array}{l}\text { Smoking } \\
\text { In past } \\
\text { At present } \\
\text { Never }\end{array}$ & $\begin{array}{l}40(64.5 \%) \\
35(59.3 \%) \\
184(64.6 \%)\end{array}$ & $\begin{array}{l}22(35.5 \%) \\
24(40.7 \%) \\
101(35.4 \%)\end{array}$ & $\begin{array}{l}62(100.0 \%) \\
59(100.0 \%) \\
285(100.0 \%)\end{array}$ & 0.742 \\
\hline Total & $259(63.8 \%)$ & $147(36.2 \%)$ & $406(100.0 \%)$ & \\
\hline
\end{tabular}

${ }^{*}$ Chi-square test

Table 1: Distribution of socio-demographic characteristics in controlled and uncontrolled hypertensive diabetic patients.

control HTN as people age. In this study, work status variable has been used to measure the physical activity level of the respondents because it has a strong relationship with HTN control. There is no significant difference in HTN control by educational level or economic hardship status. With respect to the clinical variables, we found significant differences for the following variables; regular physical exercise $(\mathrm{p}<$ $0.013)$, side effects of medicine ( $\mathrm{p}<0.000)$, forgetting to take medicine $(\mathrm{p}<0.047)$, and kidney disease $(\mathrm{p}<0.003)$, occupational stress $(\mathrm{p}<$ $0.005)$, and mental stress $(\mathrm{p}<0.020)$. Previous studies suggest that regular physical exercise plays a vital role in preventing cardiovascular disease. Moreover regular physical exercise is especially important for a person with diabetes since it helps with blood sugar control, weight loss and high blood pressure control as well. People with diabetes who exercise regularly are less likely to experience a heart attack or stroke than diabetic patients who do not exercise regularly. Physical exercise generally helps to control blood glucose levels because exercising muscle cells use more sugar and oxygen. Exercise also helps insulin to work better. Out of 406 respondents, 349 or 85.96 percent of the respondents exercise on a regular basis and it showed a significant effect on HTN control among diabetic patients $(\mathrm{p}<0.013)$. For people with diabetes, occupational stress and mental stress can take a greater toll on health. Occupational stress and mental stress increase blood sugar 
Citation: Hoque MN, Mondal NI, Moni SY, Chowdhury RK (2012) Determinants of Blood Pressure Control in Hypertensive Diabetic Patients in Rajshahi District of Bangladesh. J Biomet Biostat S7:001. doi:10.4172/2155-6180.S7-001

levels which in turn increases the pressure the blood exerts on the wall of blood vessels. On the other hand, reducing stress can help maintain normal blood pressure. Some mental stress may be a normal part of life, but too much stress can lead to emotional, psychological and even physical problems, including cardio vascular disease, high blood pressure, chest pains or irregular heart beats. Moreover, mental stress itself is a risk factor for heart disease. It is experimentally identified that a high level of psychological stress is strongly associated with HTN [12]. This study identified that most of the patients $(n=328,80.79 \%)$ did not have occupational pressure but most of the respondents had mental stress $(\mathrm{n}=263,64.78 \%)$. The $\chi^{2}$ test showed occupational pressure $(\mathrm{p}<0.005)$ and mental stress $(\mathrm{p}<0.020)$ were associated with HTN control. Cigarette smoking and salt intake contribute to cardiovascular disease. As a result, reduced salt intake and smoke cessations are highly recommended as a means to HTN control for the people with diabetes. This study revealed that 276 or 67.98 percent of the respondents did not take extra salt on their food of whom 173 or 62.70 percent can control HTN. Two hundred and eighty five (70.20\%) patients never smoked of whom 184 (64.60\%) can control HTN (Table 2). This result supports a previous study among non-diabetic smokers where patients were found to have lower BP than non-smokers. Cigarette smoking is a risk factor for HTN and smokers have a five fold increased risk of a hypertensive crisis [13]. Again, reduction in salt intake and increased physical activity [14] will reduce blood pressure and thus improve in the control of HTN as well.

Logistic regression analysis was performed to measure the relative risks of socio-demographic and clinical variables. Results of logistic regressions are presented in Table 2. The results show that the variables selected for the analysis are generally important predictors of HTN control among diabetic patients. In Bangladesh, men are more likely to control HTN compared with women. The findings show a

\begin{tabular}{|c|c|c|c|c|c|}
\hline \multirow{2}{*}{ Characteristics } & \multirow{2}{*}{ Coefficients ( $\beta$ values) } & \multirow{2}{*}{ Standard error (SE) } & \multirow{2}{*}{ Odds Ratio (OR) } & \multicolumn{2}{|c|}{ 95\% Confidence Interval (Cl) } \\
\hline & & & & Lower limit & Upper limit \\
\hline $\begin{array}{l}\text { Sex } \\
\text { Female (RC) } \\
\text { Male }\end{array}$ & $0.566^{*}$ & 0.336 & 1.761 & 0.912 & 3.400 \\
\hline $\begin{array}{l}\text { Age groups } \\
56+(R C) \\
\leq 40 \\
41-55\end{array}$ & $\begin{array}{l}0.958^{*} \\
1.501^{*}\end{array}$ & $\begin{array}{l}0.496 \\
0.246\end{array}$ & $\begin{array}{l}2.608 \\
1.663\end{array}$ & $\begin{array}{l}0.987 \\
1.028\end{array}$ & $\begin{array}{l}6.889 \\
2.690\end{array}$ \\
\hline $\begin{array}{l}\text { Education } \\
\text { No Education (RC) } \\
\text { Primary \& Secondary } \\
\text { College \& Higher }\end{array}$ & $\begin{array}{l}-0.092 \\
0.756^{*}\end{array}$ & $\begin{array}{l}0.316 \\
0.422\end{array}$ & $\begin{array}{l}0.912 \\
2.128\end{array}$ & $\begin{array}{l}0491 \\
0.930\end{array}$ & $\begin{array}{l}1.696 \\
4.869\end{array}$ \\
\hline $\begin{array}{l}\text { Work Status/physical activ- } \\
\text { ity level } \\
\text { Extremely inactive(RC) } \\
\text { Lightly active } \\
\text { Moderately active } \\
\text { Vigorously active }\end{array}$ & $\begin{array}{l}0.822^{*} \\
1.523^{*} \\
1.569^{*}\end{array}$ & $\begin{array}{l}0.446 \\
0.469 \\
0.837\end{array}$ & $\begin{array}{l}2.275 \\
4.589 \\
4.803\end{array}$ & $\begin{array}{l}0.947 \\
1.829 \\
0.931\end{array}$ & $\begin{array}{l}5.462 \\
11.518 \\
24.787\end{array}$ \\
\hline $\begin{array}{l}\text { Economic hardship } \\
\text { No }(R C) \\
\text { Yes }\end{array}$ & -0.477 & 0.310 & 0.621 & 0.338 & 1.140 \\
\hline $\begin{array}{l}\text { Physical Exercise Regu- } \\
\text { larly } \\
\text { No (RC) } \\
\text { Yes }\end{array}$ & $0.396^{*}$ & 0.327 & 1.486 & 0.783 & 2.818 \\
\hline $\begin{array}{l}\text { Took Medicine Regularly } \\
\text { No (RC) } \\
\text { Yes }\end{array}$ & 0.354 & 0.274 & 1.425 & 0.833 & 2.438 \\
\hline $\begin{array}{l}\text { Side Effect of Medicine } \\
\text { No }(R C) \\
\text { Yes }\end{array}$ & $-1.276^{*}$ & 0.493 & 0.279 & 0.106 & 0.733 \\
\hline $\begin{array}{l}\text { Forget to take Medicine } \\
\text { No }(R C) \\
\text { Yes }\end{array}$ & $-0.350^{*}$ & 0.268 & 0.705 & 0.417 & 1.192 \\
\hline $\begin{array}{l}\text { Kidney Diseases } \\
\text { No (RC) } \\
\text { Yes }\end{array}$ & $-0.581^{*}$ & 0.267 & 0.559 & 0.332 & 0.994 \\
\hline $\begin{array}{l}\text { Occupational Stress } \\
\text { No (RC) } \\
\text { Yes } \\
\end{array}$ & $-0.642^{*}$ & 0.307 & 0.526 & 0.288 & 0.961 \\
\hline $\begin{array}{l}\text { Mental Stress } \\
\text { No }(R C) \\
\text { Yes }\end{array}$ & $-0.567^{*}$ & 0.257 & 0.567 & 0.343 & 0.938 \\
\hline $\begin{array}{l}\text { Salt Intake } \\
\text { No }(R C) \\
\text { Yes }\end{array}$ & -0.233 & 0.253 & 0.792 & 0.483 & 1.300 \\
\hline $\begin{array}{l}\text { Smoking } \\
\text { At Present (RC) } \\
\text { Past } \\
\text { Never }\end{array}$ & $\begin{array}{l}0.394 \\
0.117\end{array}$ & $\begin{array}{l}0.436 \\
0.371\end{array}$ & $\begin{array}{l}1.483 \\
1.124\end{array}$ & $\begin{array}{l}0.631 \\
0.544\end{array}$ & $\begin{array}{l}3.484 \\
2.324\end{array}$ \\
\hline
\end{tabular}

Note: $\mathrm{OR}=$ odds ratio, ${ }^{*} \mathrm{p}<0.005$ or better, and $\mathrm{RC}=$ Reference category

Table 2: Logistic regression analysis of socio-demographic and Clinical variables of hypertensive diabetic patients. 
positive relationship between respondents' age and HTN control. Respondents aged 40 years or young are 2.6 times more likely to control HTN compared to respondents aged 56 years and above. Similarly, respondents aged 41-55 are 1.66 times more likely to control HTN compared with respondents aged 56 years and above. Respondents with the highest level of education (college/university) are 2.128 times more likely to control HTN than those who had no education. We did not find any significant difference between no education and primary and secondary education. Those who are lightly active in their daily physical activity they are two times more likely to control HTN compared with those who are extremely inactive in their daily physical activity. Those who are moderately or vigorously active they are almost five times more likely to control HTN than with those who are extremely inactive in their daily physical activity. There is a weak relationship between economic hardship and HTN control.

Among the clinical variables, regular physical exercise, side effects of medication, forgetting to take medicine, kidney disease, occupational stress, and mental stress are significantly associated with HTN control. The respondents who exercised regularly are 1.486 times more likely to control HTN (Odds Ratio [OR] $=1.486$, with 95\% confidence interval $[\mathrm{CI}]=0.783-2.818)$ compared with those who does not do any physical exercise. The results demonstrated that the patients who took medicine on a regular basis are 1.425 times more likely to control HTN than those who were not taking medicine on a regular basis $(\mathrm{OR}=1.425$, 95\% CI $=0.833-2.438$ ). The patients who experienced side effects of medication are less likely to control HTN compared with the patients who did not experience any side effects of the medication $(\mathrm{OR}=0.279$, 95\% $\mathrm{CI}=0.106-0.733$ ). As expected, the respondents who forgot to take medicine are less likely to control HTN compared with those who did not forget to take medicine ( $\mathrm{OR}=0.705,95 \% \mathrm{CI}=0.417-1.192)$. Kidney disease significantly differentiates the control of HTN among diabetic patients; those who suffer from kidney diseases are less likely to control HTN compared with those who do not suffer from kidney diseases $(\mathrm{OR}=0.559,95 \% \mathrm{CI}=0.332-0.994)$. The patients who experience occupational stress are less likely to control HTN than those have not experienced any occupation stress $(\mathrm{OR}=0.526,95 \% \mathrm{CI}=0.288-0.961)$. As expected, the respondents who experience mental stress are also likely to control HTN compared with those who have not experience any mental stress $(\mathrm{OR}=0.567,95 \% \mathrm{CI}=0.343-0.938)$. The respondents who take extra table salt in their food are less likely to be able to control HTN compared with those do not take extra table salt in their food. In the case of smoking, the respondents are classified into three groups as having never smoked, smoking at present, and smoked in past but not presently. As expected, the respondents who smoked in the past but are not smoking at present are 1.483 times more likely to able to control HTN than those who are smoking at present $(\mathrm{OR}=1.483,95 \%$ $\mathrm{CI}=0.631-3.484)$; and those who have never smoked are 1.124 times more likely to able to control HTN compared with those who are smoking at present $(\mathrm{OR}=1.124,95 \% \mathrm{CI}=0.544-2.324)$.

\section{Conclusion}

The main objective of this study was to examine the factors that significantly contribute to the control of high blood pressure among diabetic patients. Diabetes with HTN is currently the fastest growing disease in the world. At least 10-15\% of Bangladeshis suffer from diabetes and/or HTN. At present, it is estimated that 3.8 million or $4.8 \%$ of people in Bangladesh have diabetes and that number is expected to grow to 7.4 million or $6.1 \%$ of the population by 2025 [8]. It is worrying that this explosion in diabetes prevalence will place Bangladesh among the top ten countries in terms of number of people living with diabetes by 2025 .
The findings from the bivariate analysis show that statistically significant variations exist across most of the variables selected for the present study. Results of the chi-square and logistics regression analysis suggest it is difficult to control HTN as people age. For the diabetic patients, clinical issues were the significant factors influencing HTN. Occupational pressure, mental stress and physical exercise had independent effects on HTN. The findings of the study emphasized the importance of maintaining the care and control of HTN among diabetic patients and suggested regular physical exercise, having ongoing medical care, taking medicine on a regular basis, reducing occupational and mental pressure, maintain a healthy diet, and quit smoking may help reduce high blood pressure among diabetic patients.

\section{Acknowledgments}

The survey was conducted by the students of the Department of Population Science and Human Resource Development, in collaboration with the University of Rajshahi, Bangladesh. The authors are very grateful to them. The authors would like to acknowledge the participants, staff, and physicians of the Rajshahi Medical College Hospital and the Diabetic Center for their contribution to complete this study.

\section{References}

1. American Diabetes Association (2004) Standard of Medical Care in Diabetes Diabetes Care 29: S4-S42.

2. Yusuf S, Reddy S, Ounpuu S, Anand S (2001) Global burden of cardiovascular disease. Part II. Variations in cardiovascular disease by specific ethnic groups and geographic regions and prevention strategies. Circulation 104: 2855-2864.

3. He J, Whelton PK (1999) Elevated systolic blood pressure and risk of cardiovascular and renal disease: Overview of evidence from observational epidemiologic studies and randomized controlled trials. Am Heart J 138: $211-$ 219.

4. [No authors listed] (1998) Blood pressure, cholesterol, and stroke in eastern Asia. Eastern Stroke and Coronary Heart Disease Collaborative Research Group. Lancet 352: 1801-1807.

5. Hypertension study group (2001) Prevalence, awareness, treatment and contro of hypertension among the elderly in Bangladesh and India: A multicentre study. Bull World Health Organ 79: 490-500.

6. Moon OR, Kim NS, Jang SM, Yoon TH, Kim SO (2002) The relationship between body mass index and the prevalence of obesity-related diseases based on the 1995 National Health Interview Survey in Korea. Obes Rev 3: 191-196.

7. Wild S, Roglic G, Green A, Sicree R, King H (2004) Global Prevalence of Diabetes: Estimates for the Year 2000 and Projections for 2030. Diabetes Care 27: 1047-1053.

8. Gan D (2003) Diabetes Atlas. The International Diabetes Federation (IDF), Brussels.

9. Rahman MM, Islam J (2008) Problem with Diabetes and Awareness to its control: Experience from Diabetes Patients of Rajshahi City Corporation in Bangladesh. The Internet Journal of Health 8.

10. Cardiologist (2011) Hypertension in Diabetes Patients.

11. Allison PD (1999) Logistic Regression Using SAS: Theory and Application. Cary, NC: SAS Institute Inc.

12. Perez LH, Gutierrez LA, Vioque J, Torres Y (2001) Relation between overweight, diabetes, stress, and hypertension: A case control study in Yarumal-Antioquia, Colombia. European Journal of Epidemiology 17: 275-280.

13. Al-Mehza AM, Al-Yahya AA, Al-Qattan MM, Al-Duwaisan HS, Al-Otaibi BNMB (2004) Determinants of Poor Blood Pressure Control in Hypertensive PatientsAn Area-based Study. Kuwait Medical Journal 36: 270-274.

14. Fagard RH (1995) The role of exercise in blood pressure control: supportive evidence. J Hypertens 13: 1223-1227.

This article was originally published in a special issue, Medical statistics: Clinical and experimental research handled by Editor(s). Dr. Herbert Pang, Duke University, USA. 